\title{
Corrigendum
}

\section{Corrigendum to "Design and Impedance Modeling of a Compact Sequentially Rotated Quasi-Lumped Antenna Array for Wi-Fi Applications"}

\author{
Yazeed M. I. Qasaymeh \\ Department of Electrical Engineering, College of Engineering, Majmaah University, Al-Majmaah 11952, Saudi Arabia \\ Correspondence should be addressed to Yazeed M. I. Qasaymeh; y.qasaymeh@mu.edu.sa \\ Received 12 October 2021; Accepted 12 October 2021; Published 17 November 2021 \\ Copyright (c) 2021 Yazeed M. I. Qasaymeh. This is an open access article distributed under the Creative Commons Attribution \\ License, which permits unrestricted use, distribution, and reproduction in any medium, provided the original work is \\ properly cited.
}

In the article titled "Design and Impedance Modeling of a Compact Sequentially Rotated Quasi-Lumped Antenna Array for Wi-Fi Applications" [1], the corresponding author's e-mail address was listed incorrectly. The correct e-mail address is shown above.

\section{References}

[1] Y. M. I. Qasaymeh, "Design and impedance modeling of a Compact sequentially rotated quasi-lumped Antenna Array for Wi-Fi Applications," International Journal of Antennas and Propagation, vol. 2021, Article ID 3874794, 10 pages, 2021. 